\title{
College Students Responding to the Chinese version of Cardiff Fertility Knowledge Scale Show Deficiencies in Their Awareness: A cross-sectional survey in Hunan, China
}

\section{Yanhui Zhou}

Central South University; The first affiliated hospital of University of South China

Ting Wang

Central South University

Yanhui Cui

Central South University

Mingzhu Chen

Central South University

Jingxia Fu

Central South University

Yang Luo ( $\square$ ly603202@csu.edu.cn )

Central South University https://orcid.org/0000-0002-0706-6323

\section{Research article}

Keywords: Fertility knowledge, Fertility intention, Childbearing, College students, Awareness

Posted Date: October 15th, 2019

DOI: https://doi.org/10.21203/rs.2.16013/v1

License: (c) (i) This work is licensed under a Creative Commons Attribution 4.0 International License.

Read Full License

Version of Record: A version of this preprint was published at BMC Public Health on May 29th, 2020. See the published version at https://doi.org/10.1186/s12889-020-08937-6. 


\section{Abstract}

Background: The worldwide total fertility rate has declined, and the age pattern of childbearing and marriage has changed markedly. This trend has affected the social and economic development, especially fertility health. Previous studies indicated that incorrect perceptions of fertility can influence

the fertility choice, and postponing parenthood is associated with an increase risk of higher maternal age in direction of more pregnancy-related complications. However, little is known in China, which has a low total fertility rate. Hence, understanding the knowledge about fertility is greatly needed. The aim was to investigate the knowledge about fertility issues among college students, the related influence factors, the way of acquiring fertility knowledge, the relationship between fertility knowledge and fertility intention.

Methods : An online cross-sectional survey among Chinese college students was conducted in Hunan province from March to April in 2018. A total of 867 college students from three comprehensive universities responded to a poster invitation utilizing the Chinese version of the Cardiff Fertility Knowledge Scale (CFKS-C).

Results: The average percent correct score on the CFKS-C was $49.86 \%(S D=20.817)$, with greater knowledge significantly related to living in a city district, currently having a stable relationship, majoring in medicine/health, the year 4 or above of study, and intention to have children (all $p \otimes 0.05$ ). The lowest score was "having a healthy lifestyle makes you fertile (false)", the highest score was "a woman is less fertile after the age of 36 years (true)". And then, $81.88 \%$ participants said that they would like to have children, the average score of the importance of childbearing was $6.34(S D=2.714)$, female's score was lower than male's $(p=0.001)$. A small positive relationship was observed between the CFKS-C and the importance of childbearing $(r=0.074, p=0.035)$. Respondents said they gained most of their knowledge from the media and internet (41.36\%) and schools (38.25\%).

Conclusion: The college students have a modest level of fertility knowledge, a relatively low intention to have a child, and deficiencies in fertility health education.

Key words: Fertility knowledge; Fertility intention; Childbearing; College students; Awareness;

\section{Background}

Fertility is one of the major components of population growth and age structure change and is central to the Programme of Action of the International Conference on Population and Development. The past six decades have witnessed a major decline in world fertility, especially in the developing world [1-2]. The total worldwide fertility rate fell from almost 5 births per woman in 1950-1955 to 2.5 in 2010-2015 [3]. According to the latest data released by the National Bureau of Statistics, the total number of births in mainland China was 17.23 million by the end of 2017, which is reduced 630,000 compared with 2016, and the birth rate was $12.43 \%$, which is reduced by $0.52 \%$ o compared with 2016 and $10.9 \%$ o from 1987(23.33\%o)[4]. Although the "universal two-child" policy has implemented for two years, the number of new births and the birth rate are still declining, raising concerns in all fields. Some scholars predicted 
that the current situation of China's population is similar to that of Japan 20 years ago and that a low birth trap will occur [5]. Similar to changes in total fertility, the age pattern of childbearing and marriage has markedly changed simultaneously. The age pattern of childbearing has been shifting to higher ages, with the mean age at childbearing reaching 30 years or more [6]. In addition, postponing parenthood is associated with an increase risk of higher maternal age in direction of more pregnancy-related complications.

Reasons for low fertility are multi-factorial and often difficult to disentangle. Published literature has stated, despite changes in social and economic development, the lack of knowledge about fertility and transformation of fertility concept were crucial. An international survey of 79 countries from the International Fertility Decision-making Study (IFDMS) showed that the average correct score for fertility knowledge was $56.90 \%$ [7]. Other studies confirmed the poor fertility knowledge and fertility awareness among people at reproductive age in the United States, Sweden, Germany, Italy, Japan and other countries [8-14]. In addition, some studies have demonstrated that people, including obstetrics and gynecology resident physicians and nurses tend to underestimate age-related fertility decline and overestimate the success rate of fertility treatment [15-18]. Compared with western countries, fertility knowledge is relatively less documented in Asia. A cross-sectional study conducted in Thailand revealed a considerable knowledge gap about the factors that influence fertility was identified in reproductive-age individuals (males and females aged 18-45 years old) [19]. Japanese professor Maeda found that fertility knowledge was low [12], and women with fertility knowledge gave birth to their first child 2.34 years earlier compared with those without such knowledge [20]. Thus, fertility knowledge will affect the personal fertility choice or intention.

During these studies, college students, as a particular group, were a focus given that they are of reproductive age and face choices between their education and career versus marriage and childbearing. Previous surveys among young college students in Sweden, Italy, American, New Zealand, the results revealed that knowledge about human fertility was rather poor [14, 21-23]. In China, the proportion of the population with a college education or above has increased from $2.791 \%$ in 1998 to $13.87 \%$ in 2017 [5]. However, little is known about the level of fertility knowledge among Chinese mainland college students. Moreover, fertility health education is a cultural taboo, related courses are not be provided, and little research on how they acquire fertility knowledge is reported.

Therefore, the aim of the present study was to investigate the level of fertility knowledge among college students in Hunan Province, the related influence factors, the way of acquiring fertility knowledge, the relationship between fertility knowledge and fertility intention.

\section{Methods}

\section{Design}


A cross-sectional survey among college students was conducted in Hunan province, China, during onemonth period of March 8 to April 8, 2018.

\section{Sample and setting}

The survey was conducted in Hunan province, China. Hunan province is located in the middle of China with a student enrollment of regular institutions of higher education of 22.09 persons per 10,000 population, and 109 schools that are regular institutions of higher education are located in this province [24]. The target population in the present study was college students of regular institutions of higher education. We selected three comprehensive universities for this study by convenience sampling. Each university has more than 35,000 students who come from different provinces of China in the 2017-2018 terms. Students were recruited by open recruitment as advertised by poster. These posters included a brief description of the study and a QR code and were posted on the notice boards of each college, canteen and dormitory in the university to be seen by all students and staff. By scanning the QR code using a mobile phone, a brief description of the study, an informed consent form and the questionnaire were presented (Questionnaire star software). Questionnaire star software (Ranxing information technology company, Changsha, China), the earliest and the largest domestic online questionnaire survey and test platform, has sent more than 24.62 million questionnaires and collected more than 1.603 billion questionnaires from respondents. The online survey was open from March 8 to April 8, 2018. Participants who completed the questionnaire were provided a reward incentive via the internet. In total, 867 individuals completed the online questionnaire during the 1-month collection period. Since the focus of this study was young college students, the analysis included only respondents who were full-time college students aged 30 years or below $(\mathrm{N}=799)$.

\section{Questionnaire and study variables}

The questionnaire consisted of 25 items covering 4 domains. It was pilot tested twice with 30 college students to ensure that the instrument was understandable. The pilot data were not included in the analysis.

\section{Socio-demographic variables}

Participants stated their age in years, gender, place of birth, whether they were the only-child generation (yes/no), their discipline, relation, sexual orientation.

\section{Intentions of childbearing}

One question was investigated personal intention to have children (yes/no), one 0 to 10 -point response scale was surveyed personal perceived importance of childbearing [25]. 


\section{Fertility knowledge}

The Chinese version of the Cardiff Fertility Knowledge Scale (CFKS-C) was translated into Chinese from the original Cardiff Fertility Knowledge Scale (CFKS) developed by Boivin et al (2013) and shown to have satisfactory validity and reliability. The CFKS consists of 13 items. Three areas of knowledge about fertility are measured: risks for reduced fertility, misconceptions about fertility, and basic facts about infertility. A three-point scale of "true", "false", or "do not know" was used to rate all items. One point was given for a correct answer, and zero points were given for an incorrect or unknown answer. Scores were reported as percentages that were equal to points divided by the total number of questions. In the original CFKS, the internal consistency coefficient alpha (Cronbach's a) was 0.79 [7]. The CFKS-C was developed through Brislin's translation/back-translation method and modified through cultural adaptation and semantic analysis, the Cronbach's a coefficient was 0.827 , the test-retest reliability was 0.826 , and the Scale-Content Validity Index (S-CVI) was 0.950 with the Item-Content Validity Index (I-CVI) ranging from 0.875 to $1.000[26]$.

\section{Fertility health education}

In addition, three questions were applied to investigate their perceived knowledge of fertility issues[27]: ( $₫)$ their perceived education level of fertility-related knowledge (not at all educated, somewhat educated,

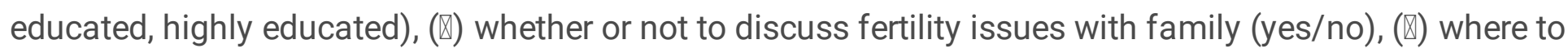
gain most of their knowledge about fertility issue (media and internet, schools, family, friends, doctors/gynecologists, and non-government organizations, other).

\section{Data analyses}

Descriptive statistics were used to describe the socio-demographic variables, and fertility knowledge. Categorical data were compared using Chi-squared tests. T-tests and analysis of variance (ANOVA) were used to compare the total scores on the CFKS-C between socio-demographic categories. Pearson's correlation was used to examine the association between importance of childbearing and CFKS-C score. The data were assessed for errors before double-entry computer input. Statistical significance was defined as a two-sided $P$ value less than 0.05. All analyses were performed using SPSS (version, 22.0) software (IBM Corp., Armonk, New York, USA).

\section{Ethics statement}

Ethical review and approval were performed by the IRB of behavioral and nursing research in School of Nursing of Central South University (Project Number 2017028). Permission to use the CFKS was obtained from the authors who developed them. A cover letter was presented to respondents to explain the aim and process of the study before the questionnaire was shown. Participation in this study was voluntary, anonymous and confidential. Returning the questionnaire was a voluntary way to click the "confirm 
submit" button via internet, so no consent form was required. To maintain anonymity, participants were asked not to provide name and telephone number. Collection of online data complied with the "Code of Conduct of Marketing Research". All data collected were treated anonymously and confidentially.

\section{Results}

\section{Participants' characteristics}

The average age of respondents was $19.69(\mathrm{SD}=1.960)$, ranging from 18 to 30 years old. Female participants accounted for $56.75 \%$ of the sample, and $68.75 \%$ of participants were single. The sociodemographic characteristics of the participants are summarized in Table 1.

Table 1 Socio-demographic characteristics of participants $(\mathrm{N}=799)$ 


\begin{tabular}{|c|c|c|c|c|}
\hline & Characteristics & $\begin{array}{c}\text { Total } \\
(\mathrm{N}=799)\end{array}$ & $\begin{array}{c}\text { Male } \\
(\mathrm{N}=345)\end{array}$ & $\begin{array}{l}\text { Female } \\
(\mathrm{N}=454)\end{array}$ \\
\hline \multirow[t]{4}{*}{ Age (years) } & Mean (SD) & 19.69 & 19.61 & $19.75(2.102)$ \\
\hline & & $(1.960)$ & $(1.756)$ & \\
\hline & Range & $18 \sim 30$ & $18 \sim 28$ & $18 \sim 30$ \\
\hline & & n (\%) & n (\%) & n (\%) \\
\hline \multirow[t]{4}{*}{ Place of birth } & City district & $322(41.55)$ & $155(44.93)$ & 177 (38.99) \\
\hline & Suburban areas & 191 (23.90) & $84(24.35)$ & 107 (23.59) \\
\hline & Villages and towns & 110 (13.77) & $44(12.75)$ & $66(14.54)$ \\
\hline & Countryside & 166 (20.78) & $62(17.97)$ & $104(22.91)$ \\
\hline \multirow[t]{2}{*}{ Only child } & Yes & $251(34.41)$ & $130(37.68)$ & $121(26.65)$ \\
\hline & No & 549 (68.59) & $215(62.32)$ & $333(73.75)$ \\
\hline Sexual & Heterosexual & $733(91.61)$ & $313(90.72)$ & 419 (92.29) \\
\hline \multirow[t]{2}{*}{ orientation } & Homosexual & $15(1.88)$ & $11(3.19)$ & $4(0.88)$ \\
\hline & Bisexuals & $52(6.51)$ & $21(6.09)$ & $31(6.83)$ \\
\hline \multirow[t]{4}{*}{ Relationship } & Single & $549(68.71)$ & $243(70.43)$ & $306(67.40)$ \\
\hline & Currently having a stable & $241(30.16)$ & $99(28.70)$ & $142(31.28)$ \\
\hline & boyfriend/girlfriend & & & \\
\hline & Engaged/married & $9(1.13)$ & $3(0.87)$ & $6(1.32)$ \\
\hline \multirow[t]{3}{*}{ Discipline } & Arts & $187(23.41)$ & $53(15.36)$ & $134(29.52)$ \\
\hline & Science & $338(42.30)$ & $196(56.81)$ & $142(31.28)$ \\
\hline & Medicine & 274 (34.29) & $96(27.82)$ & $178(39.20)$ \\
\hline Year of & 1 & $416(52.06)$ & $204(59.13)$ & $212(46.70)$ \\
\hline \multirow{3}{*}{ study } & 2 & 246 (30.79) & $95(27.54)$ & $151(33.26)$ \\
\hline & 3 & $66(8.26)$ & $22(6.37)$ & $44(9.69)$ \\
\hline & 4 or above & $71(8.89)$ & $24(6.96)$ & $47(10.35)$ \\
\hline
\end{tabular}

\section{Fertility knowledge, and influencing factors}

The average percent correct score on the CFKS-C was $49.86 \%(S D=20.817)$. Table 2 shows the fertility knowledge score for each item and ranking ordering. 
Table 2. The percentage of participants who answered correctly to each item $(\mathrm{N}=799)$

Items (correct answer)

1. A woman is less fertile after the age of 36 years. (true)

N (\%) Rank

6331

2. A couple would be classified as infertile if they did not achieve a pregnancy after 1 year of

regular sexual intercourse (without using contraception). (true)

3. Smoking decreases female fertility. (true)

$608 \quad 2$

4. Smoking decreases male fertility. (true)

5. Having a healthy lifestyle makes you fertile. (false)

6. About 1 in 10 couples are infertile. (true)

7. If a man produces sperm he is fertile. (false)

$570 \quad 4$

8. These days a woman in her 40s has a similar chance of getting pregnant as a woman in her

30s. (false)

9. If a man has had mumps after puberty he is more likely to later have a fertility problem.

(true)

10. A woman who never menstruates is still fertile. (false)

11. If a woman is overweight by more than 2 stone (13 kg or 28 pounds) then she may not be

able to get pregnant. (true)

12. If a man can achieve an erection then it is an indication that he is fertile. (false)

13. People who have had a sexually transmitted disease are likely to have reduced fertility. 
Table 3. Univariate analysis for factors related to fertility knowledge

\begin{tabular}{|c|c|c|c|c|}
\hline \multicolumn{2}{|c|}{ Variables (Socio-demographic) } & $\begin{array}{c}\text { CFKS-C } \\
\text { (Mean』SD) }\end{array}$ & $\mathrm{T} / \mathrm{F}$ value & $p$-value \\
\hline \multirow[t]{2}{*}{ Gender } & Male & $48.54(22.949)$ & -2.459 & $0.014 *$ \\
\hline & Female & $50.85(19.028)$ & & \\
\hline \multirow[t]{4}{*}{ Place of birth } & City district & $52.39(20.440)$ & $5.8193^{\#}$ & $0.001 *$ \\
\hline & Suburban areas & $44.67(20.855)$ & & \\
\hline & Villages and towns & $49.86(20.144)$ & & \\
\hline & Countryside & $50.79(21.068)$ & & \\
\hline \multirow[t]{2}{*}{ Only child } & Yes & $48.70(21.415)$ & -1.131 & 0.259 \\
\hline & No & $50.39(20.536)$ & & \\
\hline \multirow[t]{3}{*}{ Sexual orientation } & Heterosexual & 49.67 (20.858) & $1.223^{\#}$ & 0.295 \\
\hline & Homosexual & $45.64(23.703)$ & & \\
\hline & Bisexuals & $53.70(19.238)$ & & \\
\hline \multirow[t]{3}{*}{ Relationship } & Single & 48.55 (20.147) & $3.685^{\#}$ & $0.026^{*}$ \\
\hline & Currently having a stable relationship & $52.89(21.656)$ & & \\
\hline & Engaged/married & $48.72(31.009)$ & & \\
\hline \multirow[t]{3}{*}{ Discipline } & Arts & $47.43(17.638)$ & $17.459^{\#}$ & $0.000 *$ \\
\hline & Science & $46.43(22.540)$ & & \\
\hline & Medicine/Health & $55.72(19.355)$ & & \\
\hline \multirow[t]{4}{*}{ Year of study } & 1 & $47.11(20.820)$ & $6.8576^{\#}$ & $0.000 *$ \\
\hline & 2 & 52.13 (20.877) & & \\
\hline & 3 & $50.36(19.043)$ & & \\
\hline & 4 or above & 57.64 (19.585) & & \\
\hline
\end{tabular}

$* p<0.05 ; \mathrm{SD}$, standard deviation

\#, F value

As shown in Table 3, the CFKS-C scores were significantly higher in females, participants not from an only child family, engaged/married participants, participants in the medicine/health sciences discipline, 


\section{Intention of childbearing}

Among participants, $81.85 \%$ said that they would like to have children, while $18.15 \%$ reported that they had not thought about it. The CFKS-C score (mean $=50.57 \%, S D=20.670)$ of those who intention to have children were recorded, with significant higher than those who not to have children (mean $=46.63 \%, \mathrm{SD}=$ $21.245)(t=2.066, p=0.039)$. When participants were asked to rate the importance of childbearing on a scale of $0-10$, the average score was $6.34(S D=2.714)$. Women's scores (mean $=6.06, S D=2.691$ ) were lower than men's (mean $=6.72, S D=2.684)(t=3.453, p=0.001)$. A small positive relationship was observed between CFKS-C and the importance of childbearing $(r=0.074, p=0.035)$.

\section{Fertility health education}

Furthermore, $67.71 \%$ discussed fertility issues with family. More than half $(54.19 \%)$ of the participants reported that they were "somewhat educated" about fertility issues, followed by "educated' (30.91\%) and "not educated at all" (10.39\%). Only 4.51\% participants stated being "highly educated". Respondents stated that they gained most of their knowledge from the media and internet (41.36\%), schools (38.25\%), family $(9.13 \%)$, friends (6.63\%), doctors/gynecologists (2.87\%), and non-government organizations (1.5\%).

\section{Discussion}

\section{Low fertility knowledge}

The current study found that young college students in China (mainland) had a modest level of fertility knowledge. The finding was consistent with those of previous studies $[7,12]$. The IFDMS reported that the average correct score was $56.90 \%$ in 79 countries but less than $44.90 \%$ in China, and the correct score was $59.70 \%$ in the university education population [7]. In this study, though all participants are college students, the score was only $49.80 \%$, higher than the previous study in China, lower than the sample of university education population in 79 countries [7] and in Japan [12]. In general, greater fertility knowledge was associated with higher education [7-8, 20,28]. It follows that fertility knowledge remains low in China.

The findings of the present study also indicated that most of participants had misconceptions about fertility and basic facts of infertility. Table 2 reveals that the college students underestimate the incidence of infertility and the influence of mumps, and overestimate the importance of a healthy life to fertility. In fact, greater than two-thirds of participants had misperception about fertility though $89.61 \%$ reported that they were educated about fertility issue. This may have led to delay childbearing and neglect some risks 
for reduced fertility. When it comes to health issues, knowledge is the core of why people do not behave optimally based on explanatory models for behaviour change.

And then, all participants with high education displayed increased knowledge in those who were female, born in a city, those who study in the medicine/health sciences discipline, high grade students, and those currently with a stable boyfriend/girlfriend, intention to have children. These findings are consistent with previous studies, which reported that greater fertility knowledge was associated with female gender $[7,12$, 21], SES [7, 12], medical consultation for infertility [7]. This may be caused by the fertility health education persistently lagged and cultural difference. Many people are aware of the necessity of sex education, but they feel embarrassed in discussing the sex or fertility issue, especially in unmarried population [20, 21]. Moreover, a positive relationship between education and health literacy has been recorded in hypertension, diabetes, HIV health contexts [29-32]. Therefore, it is urgent to improve fertility health education in China, items with low scores and people with low scores should be concerned. Targeted promotion of fertility knowledge may raise awareness and uptake of more effective methods and improve fertility decision-making in certain population groups [33].

\section{Low intention to have children}

Approximately one-fifth (18.15\%) of the respondents stated that they did not want to have children, which was higher than previous studies in the US (14.23\%) and Sweden $(4.06 \%)[14,22]$, slightly lower than the sample in Hongkong (19.08\%) [28]. When indicating how important childbearing was to them, both male and female college students rated it as highly important (mean $=6.34, \mathrm{SD}=2.714$ ), which lower than the Denmark (male: mean = 8.2, SD = 3.1; female: mean = 9.7, SD = 2.3) [11], the US (male: mean = 8.3, SD = 2.5; female: mean $=8.5, \mathrm{SD}=2.9$ ) [22], higher than Hongkong ( mean $=6.17, \mathrm{SD}=2.98$ ) [34]. Further, male had significantly higher scores than females, which were contrary to other results $[11,14,22,34]$. These findings show in line with the fertility rate in China. This phenomenon may result from the fertility policy of the last 30 years in China. The two-child policy has been implemented for three years in China; however, in an increasing number of newlyweds put off having children or decide not to have one at all to pursue higher education or career development. A previous study provided evidence that providing fertility-related information contributes to greater reproductive knowledge and may affect childbearing intention [35]. And then, this study found that a small positive relationship was observed between CFKS-C and the importance of childbearing. So, to improve fertility knowledge may be beneficial to increase fertility rate.

\section{Lack of corrected fertility health education}

Overall, more than three-quarters of participants by self-reported had somewhat education about fertilityrelated knowledge, and more than half discussed fertility issues with family, but their correct fertility knowledge was low actually. Furthermore, the findings showed that more than half of college students obtained knowledge from media and the internet (41.36\%) instead of school and the health department. 
However, the main way of gaining fertility knowledge was school (46.00\%) and family $(20.00 \%)$ in the US [22]. These findings may disclose that an incomplete understanding of fertility issues among young people is put forward, who seek fertility information in a haphazard way from less formal sources. These results suggest that more effect education from official department such as schools and health services need to be considered to improve fertility health, and more research should be performed to evaluate educational interventions. The internet education is a double-edged sword, both right and wrong knowledge can be spread quickly. But, given that information from the internet can be obtained easily and conveniently, web-based approaches can be applied to fertility education. A randomized pretest/posttest study demonstrated that a short intervention was effective in increasing short-term knowledge about reproductive health and infertility [36]. Moreover, another studies have demonstrated the short-term efficacy of online educational approaches to increase fertility knowledge and support informed family planning decisions $[28,37]$. Given that the decision to have child is affected by various factors, fertility education should be paired with policies and practices according to local culture.

\section{Limitations}

First, the cross-sectional design of the present study had self-selection bias, which was inherent in using the convenient sampling method.

Second, the response rate and the characteristics of the non-respondents could not be ascertained because the participants were recruited by posters at the university.

Third, the population in three universities in Hunan province may not reflect the fertility knowledge level in other universities of Hunan province or other parts of China when generalizing the findings.

In addition, in order to collect more credible and comprehensive information, both quantitative and qualitative methods could be used in the future.

\section{Conclusions}

This study reveals that college students have a modest level of fertility knowledge, a relatively low intention to have a child, and deficiencies in fertility health education. Because fertility decisions should be based on correct and complete information, education institutions and providers need to take action to embed fertility education into curricula for college students and the general public.

\section{Abbreviations}

CFKS: Cardiff fertility knowledge scale

CFKS-C: The Chinese version of Cardiff fertility knowledge scale

IFDMS: International Fertility Decision-making Study 


\section{Declarations}

\section{Acknowledgements}

The authors gratefully thank professor Jacky Boivin (Cardiff University) for her authorization of CFKS and professor James A. Wiley (University of California) for his guidance.

\section{Funding}

Hunan Philosophy and Social Science Fund (18YBA441)

\section{Availability of data and materials}

The datasets used and/or analysed during the current study are available from the corresponding author on reasonable request.

\section{Authors' contributions}

YL, YHZ designed the study. YHZ, TW, YHC performed most of the data collection. YHZ undertook most of the data analysis and wrote the first draft of the manuscript. All authors contributed to data analysis, interpretation, critically reviewed and approved the final version of the manuscript.

\section{Competing interests}

The authors declared that they have no competing interests.

\section{Consent for publication}

Not applicable.

\section{Ethics approval and consent to participate}

Ethical review and approval were performed by the IRB of behavioral and nursing research in School of Nursing of Central South University (Project Number 2017028). The participants were also assured of anonymity and confidentiality of information and were informed of their right to participate or refuse participation. All data collected were treated anonymously and confidentially. 
1.United Nations, Department of Economic and Social Affairs, Population Division (2017). World Fertility Data 2017(POP/DB/Fert/Rev2017). http://www.un.org/en/development/desa/population/publications/dataset/fertility/wfd2017.shtml

2.United Nations, Department of Economic and Social Affairs, Population Division (2015). World Fertility Report 2015

(ST/ESA/SER.A/415).http://www.un.org/en/development/desa/population/publications/fertility/worldfertility-2015.shtml

3.United Nations, Department of Economic and Social Affairs, Population Division (2017), World Population Prospects: The 2017 Revision, New York: United Nations. https://esa.un.org/unpd/wpp/Download/Standard/Fertility/

4.China Statistics Press. China Statistical Yearbook 2017.

http://www.stats.gov.cn/tjsj/ndsj/2017/indexch.htm

5.Jian Song, Jing-wen Zhang. Parity, Timing of Birth, and Fertility: A Comparative Study on the Trends and Differential Mechanism of the Mean Age at Childbearing in China, Japan, and Korea, Japanese and Korean women. Population Research.2017; 41(03):3-14.

6. United Nations, Department of Economic and Social Affairs, Population Division [2015a]. World Marriage Data 2015(POP/DB/Marr/Rev2015). New York: United Nations.

http://www.un.org/en/development/desa/population/theme/marriage-unions/WMD2015.shtml

7.Bunting L, Tsibulsky I, Boivin J. Fertility knowledge and beliefs about fertility treatment: findings from the International Fertility Decision-making Study. Hum Reprod. 2013;28(2):385-97.

https://doi.org/10.1093/humrep/des402

8. Hammarberg K, Collins V, Holden C, Young K, McLachlan R. Men's knowledge, attitudes and behaviours relating to fertility. Human Reproduction Update. 2017;23(4):458-480.

https://doi.org/10.1093/humupd/dmx005

9. Hammarberg K, Zosel R, Comoy C, Robertson S, Holden C, Deeks M, et al.. Fertility-related knowledge and information-seeking behaviour among people of reproductive age: a qualitative study. Human Fertility. 2017;20(2):88-95. https://doi.org/10.1080/14647273.2016.1245447

10.Meissner C, Schippert C, von Versen-Hoynck F. Awareness, knowledge, and perceptions of infertility, fertility assessment, and assisted reproductive technologies in the era of oocyte freezing among female and male university students. J Assist Reprod Genet. 2016;33(6):719-29. DOI:10.1007/s10815-0160717-1

11.Sorensen NO, Marcussen S, Backhausen MG, Juhl M, Schmidt L, Tyden T, et al.. Fertility awareness and attitudes towards parenthood among Danish university college students. Reprod Health; 
2016;13(1):146. https://doi.org/10.1186/s12978-016-0258-1

12.Maeda E, Sugimori H, Nakamura F, Kobayashi Y, Green J, Suka M, et al.. A cross sectional study on fertility knowledge in Japan, measured with the Japanese version of Cardiff Fertility Knowledge Scale (CFKS-J). Reprod Health. 2015;12:10. https://doi.org/10.1186/1742-4755-12-10

13.Machado MC, Alves MI, Couceiro L, Silva FG, Morais DAM, Alves I.[Birth rate and fertility: knowledge and expectations analysis of 3585 university students]. Acta Med Port. 2014;27(5):601-8.

14.Lampic C, Svanberg AS, Karlstrom P, Tyden T. Fertility awareness, intentions concerning childbearing, and attitudes towards parenthood among female and male academics. Hum Reprod. 2006;21(2):558-64. https://doi.org/10.1093/humrep/dei367

15.Revelli A, Razzano A, Delle PL, Casano S, Benedetto C. Awareness of the effects of postponing motherhood among hospital gynecologists: is their knowledge sufficient to offer appropriate help to patients? J Assist Reprod Genet. 2016;33(2):215-20. https://doi.org/10.1007/s10815-015-0640-x

16.Yu L, Peterson B, Inhorn MC, Boehm JK, Patrizio P. Knowledge, attitudes, and intentions toward fertility awareness and oocyte cryopreservation among obstetrics and gynecology resident physicians. Hum Reprod. 2016;31(2):403-11. https://doi.org/10.1093/humrep/dev308

17. Hammarberg K. Knowledge, attitudes and practices relating to fertility among nurses working in primary health. Australian Journal of Advanced Nursing. 2016;34(1):6-13.

18.Mortensen LL, Hegaard HK, Andersen AN, Bentzen JG. Attitudes towards motherhood and fertility awareness among 20-40-year-old female healthcare professionals. Eur J Contracept Reprod Health Care. 2012;17(6):468-81. https://doi.org/10.3109/13625187.2012.728015

19.Na NS, Limvorapitux P, Vichinsartvichai P. Knowledge regarding factors that influence fertility in Thai reproductive-age population living in urban area: A cross-sectional study. Clin Exp Reprod Med. 2018;45(1):38-43. https://doi.org/10.5653/cerm.2018.45.1.38

20.Maeda E, Nakamura F, Boivin J, Kobayashi Y, Sugimori H, Saito H. Fertility knowledge and the timing of first childbearing: a cross-sectional study in Japan. Human Fertility.2016;19(4):275-281. https://doi.org/10.1080/14647273.2016.1239033

21. Rovei V, Gennarelli G, Lantieri T, Casano S, Revelli A, et al. Family planning, fertility awareness and knowledge about Italian legislation on assisted reproduction among Italian academic students. Reprod Biomed Online. 2010:20:873-879. https://doi.org/10.1016/j.rbmo.2010.03.024

22.Peterson BD, Pirritano M, Tucker L, Lampic C. Fertility awareness and parenting attitudes among American male and female undergraduate university students. Hum Reprod. 2012;27(5):1375-82.

https://doi.org/10.1093/humrep/des011 
23.Lucas N, Rosario R, Shelling A. New Zealand University students' knowledge of fertility decline in women via natural pregnancy and assisted reproductive technologies. Human Fertility. 2015;18(3):208214. https://doi.org/10.3109/14647273.2015.1006694

24.2017 Hunan statistical yearbook.

http://222.240.193.190/sjfb/tjnj/17tjnj/indexch.htm Accessed 7 May 2018.

25.Lampic C, Svanberg AS, Karlstrom P, Tyden T. Fertility awareness, intentions concerning childbearing, and attitudes towards parenthood among female and male academics. Hum Reprod.2006; 21:558-564. DOI: $10.1093 /$ humrep/dei367

26.Zhou YH, Guo ZQ, Song XY, Wang T, Luo Y. Cultural adaptation and validation of the Cardiff fertility knowledge scale among Chinese childbearing age population. Reproduction and Contraception. 2019; 39(2):135-138. Doi:10.3760/cma.j.issn.2096-2916.2019.02.010 (In Chinese)

27.Peterson BD, Pirritano M, Tucker L, Lampic C. Fertility awareness and parenting attitudes among American male and female undergraduate university students.Hum Reprod. 2012; 27(5):1375-82, DOI: 10.1093/humrep/des011.

28.Daniluk JC, Koert E. Fertility awareness online: the efficacy of a fertility education website in increasing knowledge and changing fertility beliefs. Human Reproduction. 2015;30(2):353-363. DOI: 10.1093/humrep/deu328

29.Reynolds R, Smoller S, Allen A, Nicholas PK. Health Literacy and Health Outcomes in Persons Living with HIV Disease: A Systematic Review. AIDS Behav. 2019; DOI: 10.1007/s10461-019-02432-9.

30.Du S, Zhou Y, Fu C, Wang Y, Du X, Xie R. Health literacy and health outcomes in hypertension: An integrative review. Int J Nurs Sci. 2018; 5(3):301-309. DOI: 10.1016/j.jnss.2018.06.001.

31.Berkman ND, Sheridan SL, Donahue KE, Halpern DJ, Crotty K. Low health literacy and health outcomes: an updated systematic review. Ann Intern Med. 2011, 155(2):97-107. DOI: 10.7326/00034819-155-2-201107190-00005.

32.Al SF, Majumdar SR, Williams B, Robertson S, Johnson JA. Health literacy and health outcomes in diabetes: a systematic review. J Gen Intern Med. 2013, 28:444-452.

https://doi.org/10.1093/humrep/deu328

33.Freilich K, Holton S, Rowe H, Kirkman M, Jordan L, McNamee K, et al.. Sociodemographic characteristics associated with the use of effective and less effective contraceptive methods: findings from the Understanding Fertility Management in Contemporary Australia survey. European Journal of Contraception \& Reproductive Health Care.2017;22(3):212-221.

https://doi.org/10.1080/13625187.2017.1304534 
34.Chan $\mathrm{CH}$, Chan TH, Peterson BD, Lampic C, Tam MY. Intentions and attitudes towards parenthood and fertility awareness among Chinese university students in Hong Kong: a comparison with Western samples. Hum Reprod. 2015;30(2):364-72. https://doi.org/10.1093/humrep/deu324

35.Williamson LE, Lawson KL, Downe PJ, Pierson RA. Informed reproductive decision-making: the impact of providing fertility information on fertility knowledge and intentions to delay childbearing. $J$ Obstet Gynaecol Can. 2014;36(5):400-405. https://doi.org/10.1016/S1701-2163(15)30585-5

36.Conceição C, Pedro J, Martins MV. Effectiveness of a video intervention on fertility knowledge among university students: a randomised pre-test/post-test study. European Journal of Contraception \& Reproductive Health Care. 2017;22(2):107-113. https://doi.org/10.1080/13625187.2017.1288903

37.Fehring RJ, Schneider M, Raviele K, Rodriguez D, Pruszynski J. Randomized comparison of two Internet-supported fertility-awareness-based methods of family planning. Contraception. 2013;88(1):2430. https://doi.org/10.1016/j.contraception.2012.10.010 